Original Article (short paper)

\title{
Is life satisfaction associated with the purpose in life of elderly hydrogymnastics practitioners?
}

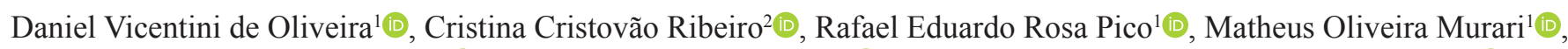
Gabriel Lucas Morais Freire ${ }^{3}$, Andressa Ribeiro Contreira ${ }^{4} \mathbb{C}^{-}$, José Roberto Andrade do Nascimento Júnior ${ }^{3} \mathbb{C}^{\circ}$

\author{
${ }^{I}$ Centro Universitário Metropolitano de Maringá, Departamento de Educação Física, Maringá, PR, Brasil; \\ ${ }^{2}$ Centro de Ensino Superior de Foz do Iguaçu, Departamento de Fisioterapia, Foz do Iguaçu, PR, Brasil; \\ ${ }^{3}$ Universidade Federal do Vale do São Francisco, Departamento de Educação Física, Petrolina, PE, Brasil; \\ ${ }^{4}$ Universidade Estadual de Maringá, Departamento de Educação Física, Maringá, PR, Brasil
}

\begin{abstract}
Aim: This cross-sectional study aimed to investigate the association between life satisfaction and purpose in the life of the elderly hydro gymnastic practitioners. Methods: A total of 92 older people of both sexes, who practice hydro gymnastics in the city of Maringá, State of Paraná, Brazil, participated in the study. A sociodemographic questionnaire, the Satisfaction with Life Scale and the purpose in life Questionnaire were used as instruments. Data analysis was carried out by using Kolmogorov-Smirnov test, Mann-Whitney U test, Kruskal-Wallis test, and Spearman's correlation test, in addition to the Path Analysis $(p<0.05)$. Results: The results showed a greater life satisfaction for the women comparing to the men $(p=0.023)$. Moreover, it was found that the elderly who perceived themselves with a better health condition obtained higher scores according to the purpose in life scale. Life satisfaction had a positive and moderate association $(\beta=0.24)$ with the purpose in the life of the elderly, which explains $6 \%$ of the variability. Conclusion: It was concluded that sex can be considered as an intervening factor when concerning life satisfaction, time of practice of hydro gymnastics and self-perceived health related to the purpose in life of the elderly. In addition, satisfaction with life was positively associated with the purpose in the life.
\end{abstract}

Keywords: life satisfaction, purpose in life, elderly people.

\section{Introduction}

Life expectancy has considerably increased over the last century ${ }^{1}$. According to the World Health Organization guidelines, by 2050 it is estimated that about $20 \%$ of the global population will consist of elderly people ${ }^{2}$. These data arouse the interest of researchers in what refers to information on the relevance for successfully aging with a good quality of life.

Under this perspective, it is seen that searching for longevity with quality should be based on the search not only for physical well-being but also psychological health, involving aspects aimed at the pursuit of happiness and wellbeing ${ }^{3,4}$. Therefore, the practice of physical exercises has been advocated for the elderly under a perspective that transcends the physical aspects of cardiorespiratory conditioning, maintenance of the muscular strength and balance, which enable their functional capacity ${ }^{5-7}$, as hydro gymnastic is one of the most sought after by the elderly population. Hydro gymnastic improves cardiorespiratory fitness, muscular endurance, balance and flexibility of the elderly. In addition to promoting socialization and better quality of life ${ }^{6}$.

There are increasing investigations that address issues related to the psychological health of the elderly who either practice or not physical exercises ${ }^{3,8-10}$. According to Cole ${ }^{11}$, these aspects include the improvement of health and wellbeing, associated with positive psychological components, including life satisfaction. This variable corresponds to a judgment regarding the individuals' perceptions about various aspects of their life, such as health, work, dwelling conditions, social relationships and autonomy ${ }^{12}$. Such perception is a process of judgment and general evaluation on life itself according to individual criteria regarding the well-being of the subject, and considering the positive and negative aspects.

Research on this variable has indicated that people who remain physically active have more positive expectations regarding their living conditions, when compared to sedentary individuals ${ }^{3,13}$. Regarding older people, specifically, the analysis on the life satisfaction has shown the expectations of the elderly about the various aspects of their life (work, family, social relationships, dwelling, health), which guide their actions towards the search for aging with quality ${ }^{3}$.

Another relevant psychological variable in the search for longevity is life purpose, that is, the way the elderly give meaning to their life and future actions ${ }^{14}$. This aspect deals with the individuals' perceptions about their values, desires and motivations ${ }^{15}$. Studies indicate that people who positively 
perceive their purpose in life give meaning to their existence, direct their actions in a propositional way, they are happier and perceive themselves as autonomous people $\mathrm{e}^{8,9,14}$. The opposite occurs when purpose in life is negatively perceived, so that individuals may exhibit a sense of existential emptiness, sadness, boredom, and hopelessness ${ }^{15}$.

According to these aspects ${ }^{16}$, emphasize the need for positively perceiving the meaning of life, especially in old age, since more optimistic points of view strengthen the psychological state of the elderly and can help them to adapt to the aging process. Therefore, a study carried out by Marí, Alves, Aerts, Camara ${ }^{17}$ which aimed at finding how middleaged adults perceive the aging process, found that people care about living longer and healthily; they care about doing regular physical activity and being engaged in new leisure activities.

It is important to identify these variables in elderly people by assessing how they cope with the aging process. However, no study that assessed the association between life satisfaction and purpose in the life of the elderly was found in the literature. Thus, this is a significant research lacuna $a^{3,14,17}$ Such a need for analysis is justified by the fact that, when considering the care of the elderly, the psychological valences are determined by the nature of relationships and experiences established, which can occur positively or negatively, and this, in turn, will influence the way the individuals interpret the environment that surrounds them, as well as the way they perceive and cope with their old age. Based on these considerations, and emphasizing that this is the first worldwide study to carry out this relationship, the present study aimed to investigate the association between life satisfaction and purpose in the life of the elderly people who practice hydro gymnastic.

\section{Methods}

\section{Participants}

The sample, intentionally chosen (nonprobability sampling), consisted of 92 elderly (60 years old or over) of both sexes, who were hydro gymnatics practitioners at one gym in the city of Maringá, PR. The elderly who showed possible cognitive deficits, evaluated by applying the MiniMental State Examination (MMSE), were excluded from the research. The MMSE consists of questions grouped into seven categories: temporal orientation, spatial orientation, three-word register, attention and calculation, recall of the three words, language and visual-constructional ability ${ }^{18}$. The cut-off points used for exclusion by the MMSE were the following: 17 for the illiterate; 22 for the elderly with 1-4-year-education level; 24 for those with 5-8-education level and 26 for the subjects who had studied for 9 years or longer. The value considered was the average obtained for each education level, minus one standard deviation. The elderly whose education level was below the cutoff point were excluded ${ }^{19}$.

The elderly with auditory deficits, which were perceived by the researchers or self-reported by the older people and that could impede the performance of the research, were also excluded. The elderly who used a walking gear; those who had a prosthesis in the hip, knee or ankle, or the ones who had undergone major surgical procedures for less than three months, and who perform another physical exercise, besides hydro gymnastics, were also excluded.

\section{Instruments}

For featuring the elderly, an identification form was used with information about sex, age, race, monthly income in minimum wage (MW), retirement, education, history of falls or near falls in the last semester, use of medicines, self-perceived health, time for doing physical exercise and weekly frequency for practicing hydro gymnastics.

The Satisfaction with Life Scale is an instrument proposed by Diener, Emmons, Larsen, Griffins ${ }^{20}$. This variable is evaluated by using five items (for example, 'in most aspects, my life is close to my ideal'), answered on a seven-point Likert scale, in which 1 corresponds to 'I completely disagree', and 7 to 'I completely agree'. The scale is intended to evaluate the judgment that the elderly make about their own life satisfaction, according to the evaluation of their values and interests. In order to interpret the results, a total score of 35 points is considered to indicate a better satisfaction with life according to the older people's perception.

For evaluating the purpose in life of the elderly, an instrument with 10 items derived from the original Ryff and Keyes'scale ${ }^{21}$ was used, which was validated by Ribeiro, Neri and Yassuda ${ }^{22}$. This is a self-reported measurement, whose responses are indicated on a six-point Likert scale, in which 1 corresponds to 'I completely agree', and 6 corresponds to 'I completely disagree'. In order to interpret the results, the highest scores were considered for the greatest life purpose.

\section{Procedures}

This is an observational cross-sectional study approved according to its ethical and methodological aspects by the Research Ethics Committee of the University Center of Maringá (UNICESUMAR) under Opinion number $1.939 .537 / 2016$.

Firstly, the list of a total of eight fitness centers that offer hydro gymnastics in the city of Maringá was obtained and analyzed by contacting the Regional Council of Physical Education of Paraná, Brazil. (CREF/PR). Secondly, contact was made with the fitness centers in order to request their authorization to invite the elderly to participate in the research and schedule the data collection. 
The elderly was approached by the researchers in the environment of the hydro gymnastics' fitness centers at different periods, before or after the practice of physical exercise. The subjects who agreed to participate in the research signed the Free Informed Consent Form (FICF) to formalize their voluntary participation. In order to avoid possible biases in the interpretation of the instruments by the elderly, the samples were conducted in the form of interviews, with an average duration of 15 minutes per elderly subject.

\section{Data analysis}

Data analysis was carried out by using the absolute and relative frequencies for the categorical variables. Considering the numerical variables, the data normality was initially assessed by using Kolmogorov-Smirnov test, thus, obtaining a non-normal distribution. Therefore, Median (Md) and Quartiles (Q1; Q3) were used to feature the results. MannWhitney U test (two groups) and Kruskal-Wallis test (three groups) were used to compare life satisfaction with purpose in the life according to the sociodemographic variables and the variables related to physical activity (three groups), followed by Mann-Whitney U test for pairs of groups. The analysis of the correlation between the variables was performed through Spearman's rank correlation coefficient with $\mathrm{p}<0.05$.

A path analysis model was used to assess the impact of life satisfaction on purpose in life of the elderly. The existence of outliers was evaluated by applying Mahalanobis square distance $\left(\mathrm{DM}^{2}\right)$, and the univariate normality of the variables through the uni and multivariate coefficients of asymmetry (ISkI $<3$ ) and kurtosis (IKuI $<10)$. Since the data did not show a normal distribution, the Bollen-Stine Bootstrap technique was used to correct the value of the coefficients estimated by the Maximum Likelihood Method implemented in AMOS software, version 22.0. There were neither $\mathrm{DM}^{2}$ values indicating the existence of outliers nor sufficiently strong correlations among the variables that indicated problems with multicollinearity (Variance Inflation Factors $<5.0$ ). Based on the recommendations by Kline [23], the interpretation of the regression coefficients had as reference the following: little effect for coefficients $<0.20$, mean effect for coefficients up to 0.49 , and strong effect for coefficients $>0.50(\mathrm{p}<0,05)$.

\section{Results}

Table 1 shows the sociodemographic characteristics of the elderly who participated in the study. According to the results, it is seen a higher prevalence of 60-69-year-old female elderly people (83.7\%), Caucasian (94.6\%), with a monthly income up to $1 \mathrm{MW}(54.3 \%)$, and complete elementary education.
Table 1. Absolute and relative frequencies of the sociodemographic profile of the elderly who practice physical exercises. Maringá, Paraná, Brazil, 2018.

\begin{tabular}{lcc}
\hline \multicolumn{1}{c}{ Variables } & $\boldsymbol{F}$ & $\mathbf{\%}$ \\
\hline Sex & 15 & 16,3 \\
Male & 77 & 83,7 \\
Female & & \\
Age group & 61 & 66,3 \\
60-69-year-old & 31 & 33,7 \\
70 years old or over & & \\
Monthly income & 50 & 54,3 \\
Up to 1 MW & 28 & 30,4 \\
1 to 2 MW & 14 & 15,2 \\
3 or more & & \\
Education & 12 & 13,0 \\
Illiterate & 21 & 22,8 \\
Incomplete elementary education & 20 & 21,7 \\
Complete elementary education & & \\
Complete high school/higher & 39 & 42,4 \\
$\quad$ Education & & \\
Color & 87 & 94,6 \\
$\quad$ White & 3 & 3,3 \\
Black & 2 & 2,2 \\
Others
\end{tabular}

MW: minimum wage

When assessing the health and physical activity profile of the elderly (Table 2), it was seen that the majority had fair or poor self-perceived health (54.3\%); the subjects had had no episodes of falls in the last six months $(85,6 \%)$ and they regularly used two or more medicines (48.9\%).

Table 2. Distribution of the health profile frequency of the elderly who practice physical exercises. Maringá, Paraná, Brazil, 2018.

\begin{tabular}{|c|c|c|}
\hline Variables & $F$ & $\%$ \\
\hline \multicolumn{3}{|l|}{ Falls in the last semester ${ }^{\mathrm{a}}$} \\
\hline Yes & 13 & 14,4 \\
\hline No & 77 & 85,6 \\
\hline \multicolumn{3}{|c|}{ Near falls in the last semester ${ }^{\mathrm{a}}$} \\
\hline Yes & 15 & 16,7 \\
\hline No & 75 & 83,3 \\
\hline \multicolumn{3}{|l|}{ Use of medicines ${ }^{\mathrm{a}}$} \\
\hline None & 3 & 3,3 \\
\hline 1 & 43 & 47,8 \\
\hline 2 or more & 44 & 48,9 \\
\hline \multicolumn{3}{|l|}{ Self-perceived health } \\
\hline Good & 42 & 45,7 \\
\hline Fair/Poor & 50 & 54,3 \\
\hline \multicolumn{3}{|l|}{ Time of practice } \\
\hline 3 months to 1 year & 28 & 30,4 \\
\hline 1,1 to 5 years & 32 & 34,8 \\
\hline More than 5 years & 31 & 33,8 \\
\hline \multicolumn{3}{|c|}{ Weekly practice frequency ${ }^{a}$} \\
\hline Twice & 36 & 39,1 \\
\hline 3 times or more & 54 & 58,7 \\
\hline
\end{tabular}

P.S.: a) Variables with absent variables. 
Regarding life satisfaction, the results of the analyses are shown in Figure 1. As it is seen, the elderly had a good level of both, life satisfaction $(\mathrm{Md}=29.0)$ and purpose in life $(\mathrm{Md}=32.0)$.

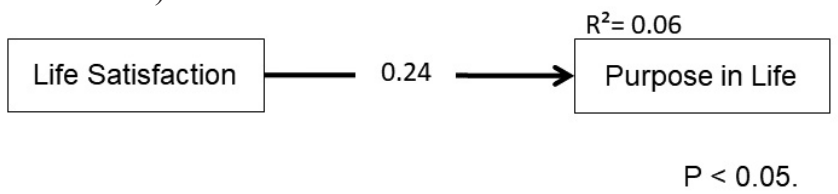

Figure 1. Regression model of the impact of life satisfaction on purpose in life of the elderly.

When comparing purpose in life and life satisfaction of the elderly according to the sociodemographic variables, a statistically significant difference was seen between the sexes regarding life satisfaction $(\mathrm{p}=0.023)$, which shows that women are more satisfied with life than men. Considering the other sociodemographic variables, no statistically significant differences were found (Table 3).

Table 3. Comparison between purpose in life and life satisfaction of the elderly who practice hydrogymnastics according to the sociodemographic variables. Maringá, Paraná, Brazil, 2018.

\begin{tabular}{lcc}
\hline \multicolumn{1}{c}{ Variables } & Life satisfaction & Life purpose \\
\cline { 2 - 3 } $\begin{array}{lcc}\text { Sex } \\
\text { Male }\end{array}$ & $24,0(20,0 ; 30,0)$ & $30,0(28,0 ; 38,0)$ \\
Female & $29,0(25,0 ; 31,5)$ & $32,0(27,5 ; 36,5)$ \\
& $(\boldsymbol{p}=\mathbf{0 , 0 2 3})$ & $(p=0,911)$ \\
Age group & & \\
60-69-year-old & $29,0(24,0 ; 32,0)$ & $32,0(28,0 ; 37,0)$ \\
70 years old or over & $29,0(25,0 ; 31,0)$ & $31,0(27,0 ; 36,0)$ \\
& $(p=0,651)$ & $(p=0,447)$ \\
Monthly incomeb & & \\
Up to 1 MW & $29,5(24,8 ; 32,0)$ & $31,5(27,0 ; 35,3)$ \\
1 to 2 MW & $29,5(23,3 ; 31,0)$ & $33,0(28,0 ; 39,8)$ \\
3 or more MW & $27,0(23,3 ; 29,3)$ & $32,5(29,5 ; 34,8)$ \\
& $(p=0,275)$ & $(p=0,383)$ \\
Education & & \\
Illiterate & & \\
Incomplete elementary & $30,5(25,5 ; 32,0)$ & $31,0(27,3 ; 36,8)$ \\
education & $30,0(25,0 ; 31,0)$ & $32,0(27,5 ; 37,0)$ \\
Complete elementary & $26,5(22,0 ; 30,0)$ & $29,0(25,3 ; 34,8)$ \\
education & & \\
Complete high school/ & $28,0(25,0 ; 31,0)$ & $33,0(29,0 ; 38,0)$ \\
Higher education & $(p=0,408)$ & $(p=0,343)$ \\
\hline
\end{tabular}

* Significant difference: $\mathrm{p}<0,05-\mathrm{a})$ Mann-Whitney U test; $\mathrm{b}$ ) Kruskal-Wallis test.

MW: minimum wage.

When comparing purpose in life and life satisfaction of the elderly according to the variables related to physical exercise practice (Table 4), a statistically significant difference was seen only for purpose in life due to the time of practice, which suggests that the elderly who have been practicing the modality for a period from 1 to 5 years had higher scores in the purpose in life scale $(\mathrm{Md}=34.5)$. In addition, it was found that the elderly who self-perceived their health as good had higher scores in the purpose in life scale $(p=0.047)$.

Table 4. Comparison between purpose in life and life satisfaction of the elderly who practice physical exercises according to self-perceived health and related to the practice of physical exercise. Maringá, Paraná, Brazil, 2018.

\begin{tabular}{lcc}
\hline \multicolumn{1}{c}{ Variables } & Life satisfaction & Life purpose \\
\cline { 2 - 3 } & Md $(\mathbf{Q} \mathbf{Q} \mathbf{Q 3})$ & Md $(\mathbf{Q 1 ; Q 3 )}$ \\
\hline Weekly frequencya & $27,5(23,3 ; 30,0)$ & $32,0(27,3 ; 36,8)$ \\
Twice & $30,0(25,0 ; 31,8)$ & $32,0(28,0 ; 36,8)$ \\
3 times or more & $(p=0,084)$ & $(p=0,898)$ \\
& & \\
Time of practiceb & $28,5(22,3 ; 30,0)$ & $30,0(28,0 ; 35,8)$ \\
3 months to 1 year & $28,5(25,0 ; 32,0)$ & $34,5(30,0 ; 38,0)^{*}$ \\
1,1 to 5 years & $29,0(25,0 ; 32,0)$ & $30,0(25,0 ; 34,0)$ \\
More than 5 years & $(p=0,342)$ & $(\boldsymbol{p}=\mathbf{0 , 0 1 7})$ \\
& & \\
Self-perceived healtha & $28,5(24,8 ; 30,3)$ & $34,0(28,0 ; 38,0)$ \\
Good & $29,0(24,0 ; 32,0)$ & $31,5(27,0 ; 34,0)$ \\
Fair/Poor & $(p=0,631)$ & $(\boldsymbol{p}=\mathbf{0 , 0 4 7 *})$ \\
&
\end{tabular}

* Significant difference: $\mathrm{p}<0,05-\mathrm{a})$ Mann-Whitney U test; $\mathrm{b}$ ) Kruskal-Wallis test.

The regression analysis showed a directly proportional correlation between life satisfaction and purpose in life of the elderly ( $p<0.05 ; r=0.27$ ). According to the regression model (Figure 2), life satisfaction had a 6\% impact on purpose in life variability, thus, indicating that the increase in the life satisfaction indicative $(\beta=0.24, p=0.020)$ had a positive effect on the purpose in life of the elderly. Therefore, it is seen that the increase of 1 standard deviation in the unit of life satisfaction causes an increase of 0.24 standard deviation in the unit of life purpose.

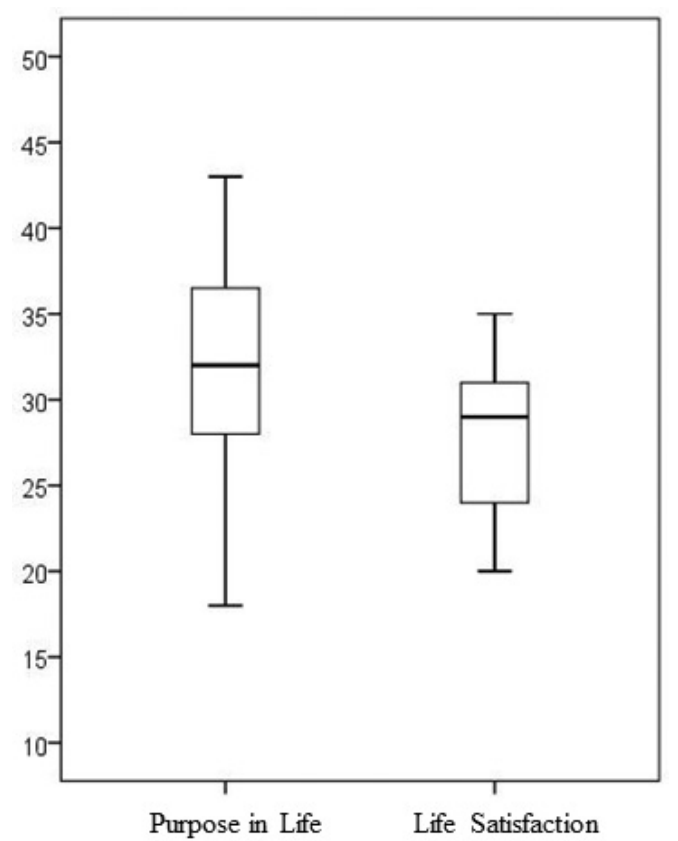

Figure 2. Descriptive statistics of purpose in life and life satisfaction of the elderly who practice hydrogymnastics. Maringá, Paraná, Brazil, 2018. 


\section{Discussion}

The main purpose of this study was to investigate the association between life satisfaction and purpose in the life of the elderly who practice hydro gymnastics. It was seen that older people who were more satisfied with life were those who showed more positive perceptions of life purposes, which suggests that having an optimistic view of life can influence short, mediumand long-term purposes. In addition, women were more satisfied with their lives than men.

As shown in the analysis, life satisfaction seems to be an intervening factor on the purpose in life of the elderly, and the constructs have a shared variance of $6 \%$. Therefore, it is seen that the elderly, when positively assessing their living conditions (work, social relationships, quality of life, health and dwelling conditions are more optimistic about their life expectancies and can cope with the aging adversities more enjoyably and positively. These aspects are reinforced by Vieira and Aquino ${ }^{8}$ research with elderly people carried out in the Brazilian state of Pernambuco. Such a study showed that the more the elderly perceive themselves to be willing and having vitality, the more they make sense of their lives, feeling energized and confident when concerning their future attitudes. The authors emphasize that, when they positively perceive their life purpose, the elderly have their psychological state positively stimulated, which reflects on the other health biological dimensions ${ }^{8}$.

The aspects identified in this research about the way the elderly perceive their living condition are considered good and can be the motivation sources for the elderly to start physical exercise (hydrogymnastics) as a way to improve health aspects. According to Silva, Castanho, Chimiazzo, Barreira, Fernandes ${ }^{10}$ one of the main interests of the elderly regarding their insertion into physical activity programs are the issues related to health, socialization and stress control. The present study, specifically, did not address the motivational factors for the practices as its main purpose, but it can be inferred that the very insertion of the elderly in the hydrogymnastics program is a beneficial way to reduce the functional limitations resulting from the aging process, in addition to improving social relationships and increasing the search for ways to feel pleasure and well-being.

Regarding the sociodemographic analysis, sex was identified as an intervening factor on the life satisfaction of the elderly, since women showed higher scores in this aspect when compared with men. A study by Lucas, Freitas, Oliveira, Machado, Monteiro ${ }^{13}$ with adolescents of both sexes obtained opposite results to the ones of this research regarding life satisfaction. The authors observed a slight superiority of the results shown for the male adolescents, in addition to identifying that at this stage of life boys are more physically active and inserted in programs of physical and sports activities, which may contribute to higher perceptions in these aspects when compared to the girls.

The findings of the present study are corroborated by information in the literature related to the fact that the women inserted in practices of physical activities feel more satisfied with their living conditions, which ends up implying positively on other psychological characteristics, such as confidence, self-esteem, reduced levels of depression, feelings of appreciation ${ }^{25}$, thus, contributing to their self-perceived satisfaction with life in a more optimistic way. In addition, it is worth mentioning that in this age group, women show a greater life expectancy compared with men and a greater concern with health-related aspects, which increases their participation in physical exercise practice and initiative for insertion in such practices ${ }^{10}$.

When comparing the purpose in the life of the elderly according to the time they have been practicing physical exercise, it was seen that the period from 1 to 5 years is sufficient so that the elderly has positive perceptions of their purpose in life. Studies have shown that the practice of physical exercises is not limited only to physiological and functional capacity (cardiorespiratory fitness, localized muscular resistance, balance, flexibility, among others) but also to psychological ones ${ }^{4,26}$. Therefore, the elderly inserted in these practices feel connected to the social groups, and, consequently, valued, thus improving their affective state with greater optimism to cope with life.

Gomes, Lima, Duarte ${ }^{27}$ corroborate these findings by pointing out that the elderly who regularly practice physical activities are more motivated to perform them, showing less social physical anxiety and higher rates of self-esteem. Lucas, Freitas, Oliveira, Machado, Monteiro ${ }^{13}$. complement that the regular practice of physical activity significantly increases the levels of well-being and life satisfaction of the individuals, which reinforces the results evidenced in this research.

It is also worth mentioning that the results of the present research pointed out that the elderly who perceive themselves with good health conditions also had greater results regarding purpose in life. In his research, Vieira ${ }^{9}$ showed that the elderly with a better perception of vitality (the ones who feel functionally vigorous and independent) have a greater sense of life (life purpose), which may evidence that they feel more willing to plan actions related to health care and functionality. Under this perspective, it is possible to infer that the elderly who participated in the present study, when perceiving good health conditions, are motivated to search for positive strategies to maintain longevity, doing exercise as a form of physical and mental well-being.

Under this perspective, studies indicate that the insertion of the elderly in physical activity programs has socialization as one of the central axes as a form of motivation for the practice ${ }^{28-29}$, so that when they feel bound and belonging to the social groups, the elderly perceive themselves more autonomous to cope with their daily activities. Therefore, it can be understood that the improvement of the health condition of the elderly transcends the biological dimension. This highlights the potential of the exercises on the affective and social aspects, which become protective factors for the appearance of other pathologies resulting from the aging process.

Despite the significant contributions of the present study on the association between life satisfaction and purpose in life of the elderly, some limitations need to be highlighted. Firstly, measuring either the training parameters of the elderly or the levels of physical activity were not considered as criteria for the analysis. Secondly, it was emphasized that the data cannot be generalized for all the elderly who practice physical exercises, since only life satisfaction and purpose in life of the older people who practice hydro gymnastics was assessed, thus, the other 
modalities of physical exercises were not included. A third limitation refers to the cross-sectional design of the research that prevents the inference of causal relations. Another limitation is the absence of a control group to compare the results, and the sample selection form (non-probabilistic)

The positive associations between life satisfaction and purpose in life of the elderly enable to understand the relevance of the good evaluations of the elderly regarding their different aspects of life (social relationships, dwelling conditions, autonomy, functionality), which significantly reflect on the purpose of life, giving better meaning to life and support for coping with adversity. These elements are protectors for a healthy aging process.

Based on the results found, the relevance of assessing these aspects in the elderly is shown, which allows them to initiate and persist in practicing physical exercises, as well as in using their strategies to maintain longevity. Such information is essential for the professionals who work with this population (physical education teachers, physiotherapists, occupational therapists) in order to understand the intervening factors about their motivations for doing exercises. Under this perspective and considering further investigations, evaluating other aspects that focus on the psychological characteristics of the elderly beyond life satisfaction and purpose in life is suggested, such as self-esteem, resilience, hope and religiosity.

\section{Conclusions}

This study aimed at investigating the association between life satisfaction and purpose in life of the elderly who practice physical exercise. In general, the results showed that the elderly had good perceptions on life satisfaction and life purpose; women had more positive perceptions than men. The practice of the modality for a while, from 1 year to 5 years, and the good health condition were intervening factors for the great purpose in the life of the elderly, which indicates that the practice of physical exercises can focus on people' psychological aspects.

\section{References}

1. Barber SE, Forster A, Birch KM. Levels and patterns of daily physical activity and sedentary behavior measured objectively in older care home residents in the United Kingdom. J Aging Phys Act. 2015;23(1):133-43; doi: 10.1123/japa.2013-0091.

2. Organización Mundial de la Salud. Informe mundial sobre el envejecimiento y la salud [in spanish]. Available from URL: http:// apps.who.int/iris/bitstream/10665/186466/1/9789240694873_spa. pdf?ua $=1$.

3. Joia LC, Ruiz T, Donalisio MR. Conditions associated with satisfaction with quality of life in an elderly population. [in portuguese]. Rev Saúde Pública. 2008;41(1):131-8; doi: 10.1590/ S0034-89102007000100018.

4. Pinto JM, Fontaine AM, Neri AL. The influence of physical and mental health on life satisfaction is mediated by self-rated health: A study with Brazilian elderly. Arch Gerontol Geriatr. 2016;1(65):10410; doi: 10.1016/j.archger.2016.03.009.
5. Freitas CV, Edson K, Santana C, Carneiro SR. Evaluation of fragility, functional capacity and quality of life of the elderly attended at the geriatrics outpatient clinic of a university hospital. [in portuguese]. Rev Bras Geriatr Gerontol. 2016;119-28; doi: 10.1590/1809-9823.2016.14244.

6. Siqueira AF, Rebesco DB, Amaral FA, Maganhini CB, Agnol SMD, Furmann M, et al. Effect of a program of aquatic physiotherapy in equilibrium and functional capacity of elderly. [in portuguese]. Rev Saúde Pesqui. 2017;10(2):331-8; doi: 10.17765/1983-1870.2017v1 0n2p331-338.

7. Agostini CM, Rodrigues VS, Guimarães AC, Damázio LCM, Vasconcelos NN. Analysis of motor performance and body equilibrium of active elderlys with arterial hypertension and type 2 diabetes. [in portuguese]. Rev Aten Saúde. 2018;16(55):29-35; doi: 10.13037/ras.vol16n55.4690.

8. Vieira DCR, Aquino TAV. Subjective Vitality, Sense in Life and Religiosity in the Elderly: A Correlational Study. [in portuguese]. Temas Psicol. 2016;24(2):483-94; doi: 9788/TP2016.2-05Pt.

9. Vieira DCR. OA velhice em uma dimensão existencial: perspectivas entre sentido de vida, religiosidade, vitalidade e temporalidade. João Pessoa. Dissertação [Mestrado em Ciências das Religiões]Universidade Federal da Paraíba; 2014.

10. Silva ANC, Castanho GKF, Chimiazzo JGC, Barreira J, Fernandes PT. Motivational factors related to the practice of physical activities in the elderly. [in portuguese]. Psicol Estudo. 2016;21(4):677-85; doi: 10.4025/psicolestud.v21i4.32198.

11. Cole SW, Hawkley LC, Arevalo JM, Sung CY, Rose RM., Cacioppo JT. Social regulation of gene expression in human leukocytes. Genome biology. 2007;8(9), R189; doi: 10.1186/gb-2007-8-9-r189.

12. Sposito G, Neri A, Yassuda M. Advanced activities of daily living (AADLs) and cognitive performance in community-dwelling elderly persons: Data from FIBRA study - UNICAMP. [in portuguese]. Rev Bras Getr Gerontol. 2016;9(1):7-20; doi: 10.1590/1809-9823.2016.15044.

13. Lucas C, Freitas C, Oliveira C, Machado M, Monteiro M. Exercise and satisfaction with life. [in portuguese]. Psytech \& Health Journal. 2018;1(2):38-47; doi: 10.26580/PTHJ.art8.2018.

14. Aquino TAA, Gouveia VV, Gomes ES, Sá LBM. The perception of the meaning of life in the life cycle: a temporary perspective. [in spanish]. Avances en Psicologia Latinoamericana. 2017;35(2):37586; doi: 10.12804/revistas.urosario.edu.co/apl/a.3728.

15. Garber CE, Blissmer B, Deschenes MR, Franklin BA, Lamonte MJ, Lee IM, et al. Quantity and quality of exercise for developing and maintaining cardiorespiratory, musculoskeletal, and neuromotor fitness in apparently healthy adults: guidance for prescribing exercise. Med Sci in Sports Exerc. 2011;43(7):1334-59; doi: 10.1249/ MSS.0b013e318213fefb.

16. Oliveira EKS, Silva JP. Sense of life and envelhecimento: relationship between the pillars of logotherapy and psychological well-being. [in spanish]. Rev Logos Exist. 2013;2(2):135-46.

17. Mari FR, Alves GG, Aerts DRG, Camara S. The aging process and health: what do middle-aged people think about it?. [in portuguese]. Rev Bras Geriatr Gerontol. 2016; 9(1), 35-44; doi: 101590/1809-9823.2016.14122.

18. Folstein MF, Folstein SE, McHugh PR. Mini mental State: a practical method for grading the cognitive state of patients for clinician. J Psychiatric Res. 1975; 12(1):189-98. 
19. Brucki SMD, Nitrini R, Caramelli P, Bertolucci PHF, Okamoto IH. Suggestions for using the mini-mental state exam in Brazil. Arq Neuropsiq. 2003;61(3):777-81; doi: 10.1590/ S0004-282X2003000500014.

20. Diener E, Emmons R, Larsen R, Griffins S. The satisfaction with life scale. J Personal Assesm, 1985,49(1):71-75; doi: 10.1207/ s15327752jpa4901_13.

21. Ryff CD, Keyes CLM. The structure of psychological well-being revisited. J Pers Soci Psychol. 1995;69(4):719; doi: 10.1037/0022-3514.69.4.719.

22. Ribeiro, Neri, Yassuda. Semantic-cultural validation and internal consistency analysis of the Purpose in Life Scale for brazilian older adults. Dement Neuropsychologia. 2018;12(3):244-249.

23. Kline R. B. Principles and practice of structural equation modeling. New York: The Guilford Press. 2012.

24. Vieira JLL, Porcu M, Rocha PGM. The practice of regular physical exercises as complementary therapy to the treatment of women with depression. [in portuguese]. J Bras Psiquiatr. 2007;56(1):23-8; doi: 10.1590/S0047-20852007000100007.

25. Chung P-K, Zhao Y, Liu J-D, Quach B. A canonical correlation analysis on the relationship between functional fitness and health-related quality of life in older adults. Arch Gerontol Geriatr. 2017;68:44-8; doi: 10.1016/j.archger.2016.08.007.

26. Gomes A. Sintomas depressivos e diabetes: uma análise em idosos praticantes de atividade física. Campina Grande. Monografia [Licenciatura em Educação Física] Universidade Estadual da Paraíba, 2015.
27. Castro MR, Lima LHR, Duarte ER. Recreational games for the elderly: an analysis based on the perception of the elderly. [in portuguese]. Rev Bras Ciênc Esporte. 2016;38(3):283-9; doi: 10.1016/j. rbce.2015.11.004.

28. Smith GL, Banting L, Eime R, O’Sullivan G, Van Uffelen JG. The association between social support and physical activity in older adults: a systematic review. Int J Behav Nutr Phys Act. 2017;14(1):56; doi: 10.1186/s12966-017-0509-8.

\section{Corresponding author}

Daniel Vicentini de Oliveira

Metropolitan University Center of Maringá. Physical education department. Maringá, Paraná, Brazil. Mauá avenue, 2854. Zone 03. 87013-160.

Email: d.vicentini@hotmail.com

Manuscript received on March 5, 2019

Manuscript accepted on May 3, 2019

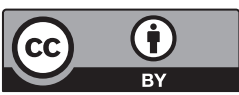

Motriz. The Journal of Physical Education. UNESP. Rio Claro, SP, Brazil - eISSN: 1980-6574 - under a license Creative Commons - Version 4.0 